\title{
ASCORBIC ACID
}

11

DEHYDROASCORBIC ACID

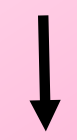

$\mathrm{C}_{6}$ DICARBOXYLIC ACID

in blood at $\mathrm{pH} 7.4$

Reconstructed manuscript version of

Analytical Biochemistry 72 (1976) 623-628

Link to publisher: doi:10.1016/0003-2697(76)90575-3

\section{Conversion of dehydroascorbic acid to a branched hexaric acid} in neutral and alkaline aqueous solution

Lars Löwendahl and Göran Petersson

$\underline{\text { Recent e-book on antioxidants in Swedish by Göran Petersson }}$ 


\title{
Conversion of Dehydroascorbic Acid to a Branched Hexaric Acid in Neutral and Alkaline Aqueous Solution
}

\author{
LARS LÖWENDAHL AND GÖRAN PETERSSON \\ Chalmers University of Technology, Department of Engineering Chemistry, \\ Göteborg, Sweden
}

\begin{abstract}
Dehydroascorbic acid is shown to be converted to 2-(threo-1,2,3-trihydroxypropyl)tartronic acid in aqueous alkaline solutions. The structure of the acid was determined by mass spectrometry of its acyclic $\mathrm{Me}_{3} \mathrm{Si}$ derivative. Mass spectrometric and chromatographic data are compared with those of related compounds. The acid is formed by a benzilic acid rearrangement of the intermediate 2,3-hexodiulosonic acid. The rate of formation at $38^{\circ} \mathrm{C}$ was studied quantitatively by GC. It increases at increased alkalinity but is significant even at physiological $\mathrm{pH}$. The presence of oxygen does not substantially influence the reaction.
\end{abstract}

\section{Introduction}

Destruction of ascorbic acid is thought to occur mainly via oxidation to dehydroascorbic acid. Therefore, knowledge of the decomposition products of the latter acid appears to be essential, especially in view of the increasing consumption of ascorbic acid. The initial conversion to threo-2,3-hexodiulosonic acid has been studied previously both in vitro and in vivo $(1,2)$. The present paper describes the application of recently developed analytical methods (3) to the study of a secondary, more stable product. This compound was first discovered on alkaline treatment of ascorbic acid (4) when, incidentally, air was not excluded in one of the experiments. 


\section{METHODS}

\section{Alkaline Treatment and Quantitative Analysis}

Dehydroascorbic acid (Fluka AG, practicum) was suspended in boiled water (70 $\mathrm{mg}$ in $5.0 \mathrm{ml}$ ) and injected into $30 \mathrm{ml}$ of oxygen-free water covered with paraffin and kept stirred at $38^{\circ} \mathrm{C}$. The $\mathrm{pH}$ was first raised and then kept constant at a predetermined value by the addition of a boiled solution of $\mathrm{NaOH}(0.1 \mathrm{M})$ with an automatic titrator.

Samples $(2.0 \mathrm{ml})$ were withdrawn with a syringe and a similar volume of an aqueous standard solution containing arabinitol and D-glycero-D-galactoheptitol was added. The $\mathrm{pH}$ of the solution was decreased to 6.1 by the addition of $0.05 \mathrm{M} \mathrm{HCl}$. This $\mathrm{pH}$-value was found to be sufficiently low to stop the formation of the acidic product to be analyzed and sufficiently high to prevent subsequent formation of lactones. The solution was evaporated to dryness at $33^{\circ} \mathrm{C}$ in a rotary vacuum evaporator, and the residue, including the sodium salts of the acids, was converted to trimethylsilyl $\left(\mathrm{Me}_{3} \mathrm{Si}\right)$ derivatives and studied by GC according to previously described methods (3). Analysis on QF-l at $160^{\circ} \mathrm{C}$ permitted the separation of the major reaction product and the two alditols from interfering compounds. Peak areas were determined from peak height and peak width at half peak height. Corrections for response factors (5) and for the changes in the volume of the reaction mixture were made in the final calculation of yields.

\section{Mass Spectrometric Identification}

In Fig. lA, the mass spectrum of the $\mathrm{Me}_{3} \mathrm{Si}$ derivative of the acidic product is reproduced. The spectrum was obtained by GC-MS on a LKB 9000 instrument under the same experimental conditions as in recent MS studies of $\mathrm{Me}_{3} \mathrm{Si}$ derivatives of unbranched aldaric and deoxyaldaric (6) and branched deoxyaldaric (7) acids.

The mle 627 ions are likely to be the M-15 ions which are characteristic of most $\mathrm{Me}_{3} \mathrm{Si}$ derivatives. The mass and abundance suggest a hexaric acid (6). The prominent peaks at mle 103, 205, and 307 indicate the presence of a 1,2,3trihydroxypropyl moiety. In strong support of the implicated structure (Fig. lA), a previously studied McLafferty-type rearrangement of $\mathrm{Me}_{3} \mathrm{Si}$ groups (8) predicts the formation of mle 408 ions (Fig. IC). For comparison, the spectrum of the previously identified (4), branched tetraric acid is reproduced (Fig. 1B). 
A large metastable peak ( $m *=378$-380; calc. 378.6) demonstrates the formation of the abundant mle 393 ions from the mle 408 ions for both acids and supports the prediction of identical ions. The remaining prominent features of the spectra are anticipated on comparison with the fragmentation pattern of the unbranched aldaric acids (6).

To confirm the structure, a sample of the acid was evaporated with $3 \mathrm{M} \mathrm{HCI}$ and reduced with $\mathrm{KBH}_{4}$ (cf. 4). Analysis by GC-MS after silylation demonstrated the presence of two major compounds. By comparison with reference spectra (9), the most prominent product was shown to be 2-C-(hydroxymethyl)pentonic acid(s). The spectrum of the other component indicated the second anticipated product, a 2-C-(hydroxymethyl)pentitol.

On chemical grounds the 2-(1,2,3-trihydroxypropyl)tartronic acid obtained from dehydroascorbic acid (threo-2,3-hexodiulosono-l,4-lactone) is concluded to be the threo isomer. In the experiment with ascorbic acid referred to in the introduction, another less prominent product gave rise to an almost identical spectrum. Consequently, this compound is the erythro isomer to be expected from dehydroisoascorbic acid (erythro-2,3-hexodiulosono-l,4-lactone) .

\section{Chromatographic and Preparative Data}

For separations and routine identifications of the aldaric acids, ion exchange chromatography as well as GC after conversion to $\mathrm{Me}_{3} \mathrm{Si}$ derivatives was found to be satisfactory methods. The GC data (Table 1 ) are directly comparable with those previously given for other hydroxy acids (3). For ion exchange chromatography (Dowex l-X8, 14-17 $\mu \mathrm{m}$, acetate form) 0.3 M NaOAc + $2 \mathrm{M}$ HOAc was used as the eluent (4). The $\mathrm{D}_{\mathrm{v}}$ values were 8.4 for the erythro and 12.1 for the threo isomer of the $\mathrm{C}_{6}$ acids and 23.1 for the $\mathrm{C}_{4}$ acid.

For preparative purposes, a suspension of $140 \mathrm{mg}$ dehydroascorbic acid was treated as described above at $\mathrm{pH} 10.8$ for $3.5 \mathrm{hr}$. The products were separated on a preparative anion exchange column $(1$ x $86 \mathrm{~cm}$, Dowex 1-X8, 20-27 $\mu \mathrm{m}$, acetate form) and detected with a differential refractometer. The major component appeared as a single band, and the corresponding fraction was evaporated to dryness after removal of the sodium ions by cation exchange. Analysis by GC indicated that the residue was the pure product. The yield was $64 \%$ as calculated both from the alkali consumption at $\mathrm{pH} 10.5$ under $\mathrm{N}_{2}$ and from the weight of the fraction. 


\section{RESULTS AND DISCUSSION}

\section{Formulation of the Reaction}

The rapid saponification of dehydroascorbic acid above $\mathrm{pH} 7(1,2)$ indicates that threo-2,3-hexodiulosonic acid is an intermediate in the formation of the hexaric acid. The branched structure of the product is consistent with its formation from the 2,3-diulosonic acid by a benzilic acid rearrangement. A similar reaction explains the formation of 2-(2,3-dihydroxypropyl)tartronic acid via 4-deoxy-2,3hexodiulosonic acid from ascorbic acid (4). The rearrangement is likely to be characteristic of 2,3-diulosonic acids in aqueous alkaline solutions (7).

The reactions shown in Fig. 2 should be irreversible under the experimental conditions applied. However, dehydroascorbic acid and the 2,3-diulosonic acid are likely to be interconverted with hydrated and hemiacetal forms. The GC results for the incompletely reacted samples indicated the presence of such hemiacetal components.

\section{Influence of Alkalinity}

The results presented in Fig. 3 roughly correspond to an anticipated first-order dependence on $\left[\mathrm{OH}^{-}\right]$of the rate of the slow rearrangement reaction. The influence of the rapid first reaction step should be negligible. On the other hand, a varying proportion of the 2,3-diulosonic acid in the acyclic diketo form should affect the reaction rate. At $\mathrm{pH} 10.8$, the complete consumption of the 2,3diulosonic acid corresponds to an approximately $60 \%$ yield. This demonstrates that the branched hexaric acid is the predominant product but also indicates minor side-reactions. It is noteworthy that decarboxylation has been shown to be significant in pure aqueous solutions (10).

\section{Influence of Oxygen}

To prevent oxidative cleavages, air was carefully excluded as described in the experimental section. However, no additional products were detected when the experiments at $\mathrm{pH} 8.5$ were made without paraffin oil. Hence, the results are not much influenced if no precautions to exclude air are taken. This indicates that the hexaric acid is formed as a major product when ascorbic acid is used as an antioxidant in basic or neutral environment. 
Even with violent bubbling of oxygen through the solution at $\mathrm{pH} 9.9$, the formation (by weight) of the hexaric acid exceeded that of glyceric, threonic, and oxalic acids together. By contrast, the same treatment of ascorbic acid resulted in the expected rapid formation of almost exclusively threonic and oxalic acids. It is concluded that under the conditions applied, dehydroascorbic acid is not an intermediate in the oxidative cleavage of ascorbic acid. This is consistent with the cleavage of other carbohydrates by oxygen-alkali via enediolates without the frequently postulated intermediate formation of dicarbonyl compounds.

\section{Physiological Aspects}

In its metabolic action as a hydrogen donor, ascorbic acid is converted to dehydroascorbic acid. In mammals, dehydroascorbic acid can be actively reduced to ascorbic acid, but as expected from the in vitro behavior it is also converted to the 2,3-hexodiulosonate (1). The results of an extended in vitro study at physiological $\mathrm{pH}$ are shown in Fig. 4. Although the benzilic acid rearrangement is normally associated with a high alkalinity, a fairly high rate of conversion to the hexaric acid is observed. The results suggest that dehydroascorbic acid may be converted to the hexaric acid in the organism as well. This appears to be of potential medical interest particularly in connection with the current interest in large doses of ascorbic acid.

\section{ACKNOWLEDGMENT}

The authors thank Miss Mary Lundin for skilful experimental assistance.

\section{REFERENCES}

1. Penney, J. R., and Zilva, S. S. (1943) Biochem. J. 37,403-417.

2. Velisek, J., Davidek, J., and Janicek, G. (1972) Collection Czech. Chem. Commun. 37, 1465-1470.

3. Petersson, G. (1974) Carbohyd. Res. 33, 47-61.

4. Löwendahl, L., Petersson, G., and Samuelson, O. (1975) Acta Chem. Scand. 29, 975-980.

5. Verhaar, L. A. Th., and DeWilt, H. O. J. (1969) J. Chromatogr. 41, 168-179.

6. Petersson, G. (1972) Org. Mass Spectrom. 6, 565-576.

7. Petersson, G. (1972) Carbohyd. Res. 43, 1-8.

8. Petersson, G. (1972) Org. Mass Spectrom. 6, 577-592.

9. Ericsson, B., Lindgren, B.O., and Theander, O. (1974) Cellul. Chem. Technol. 8, 363-385.

10. Wisser, K., Heimann, W., and Mögel, E. (1972) Chem. Mikrobiol. Technol. Lebensm.1, 106-109. 

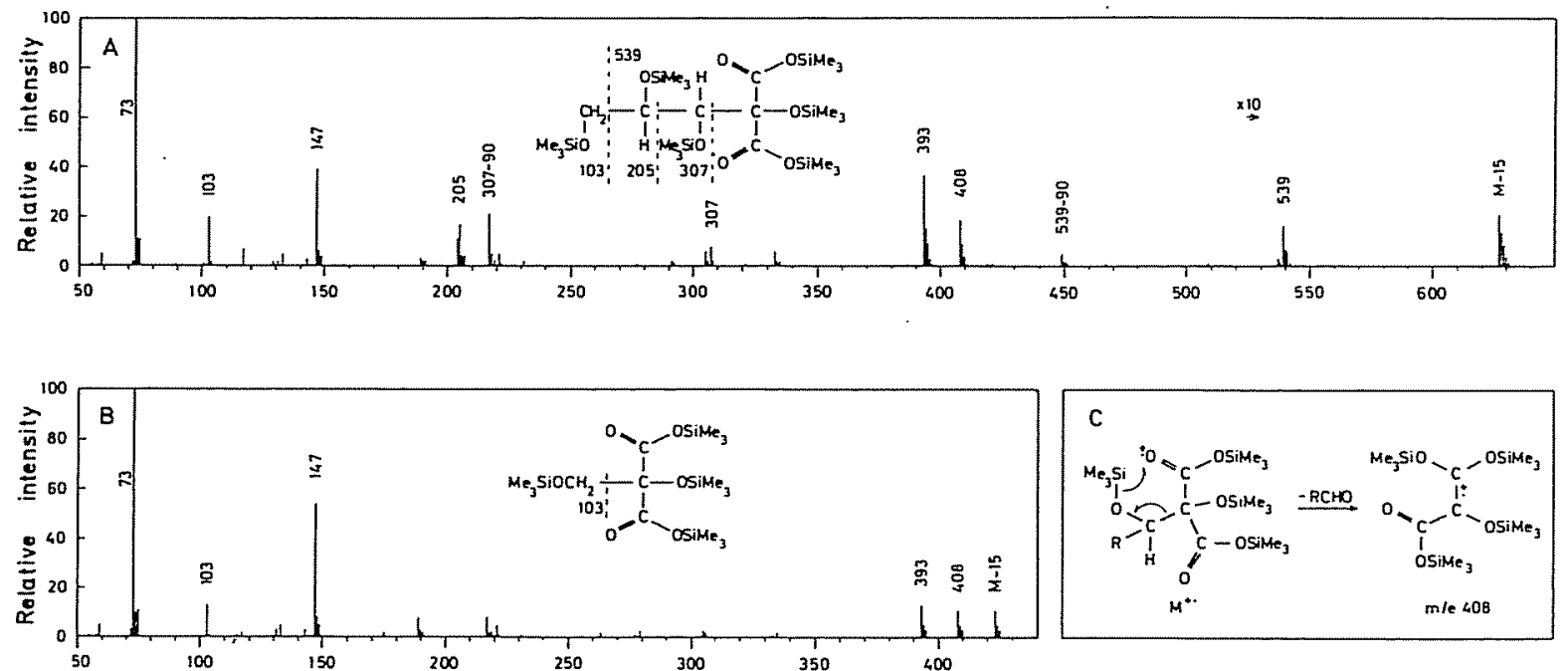

Figure 1. Mass spectra at $70 \mathrm{eV}$ of the $\mathrm{Me}_{3} \mathrm{Si}$ derivatives of 2-(threo-1,2,3-trihydroxypropyl)tartronic acid (A) and 2-(hydroxymethyl)tartronic acid (B). Formation of structure-specific $m / e 408$ ions from the molecular ions (C).

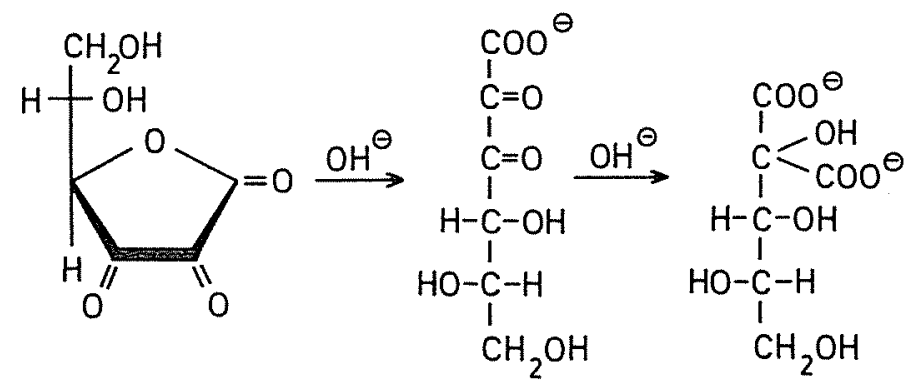

Figure 2. Schematic reaction formula for the alkaline conversion of dehydroascorbic acid to 2-(threo-1,2,3-trihydroxypropyl)tartronic acid.

\begin{tabular}{lllll} 
& $\begin{array}{l}\mathrm{OV}-1 \\
160^{\circ} \mathrm{C}\end{array}$ & $\begin{array}{l}\mathrm{OV}-17 \\
160^{\circ} \mathrm{C}\end{array}$ & $\begin{array}{l}\mathrm{QF}-\mathrm{I} \\
120^{\circ} \mathrm{C}\end{array}$ & $\begin{array}{l}\mathrm{XE}-60 \\
120^{\circ} \mathrm{C}\end{array}$ \\
\hline $\begin{array}{l}\mathrm{C}_{4} \text {-Acids } \\
\text { 2-(Hydroxymethyl)tartronic }\end{array}$ & 0.152 & 0.261 & 0.273 & 0.266 \\
$\begin{array}{l}\mathrm{C}_{6} \text {-Acids } \\
\text { 2-(erythro-1,2,3-trihydroxypropyl)- } \\
\text { tartronic }\end{array}$ & 1.310 & 1.801 & 1.762 & 1.932 \\
$\begin{array}{l}\text { 2-(threo-1,2,3-trihydroxypropyl)- } \\
\text { tartronic }\end{array}$ & 1.377 & 1.904 & 1.822 & 1.991 \\
\hline
\end{tabular}

Table 1. Gas Chromatography of branched aldaric acids as $\mathrm{Me}_{3} \mathrm{Si}$ derivatives (3). Retention times on four stationary phases relative to the $\mathrm{Me}_{3} \mathrm{Si}$ derivative of glucitol. 


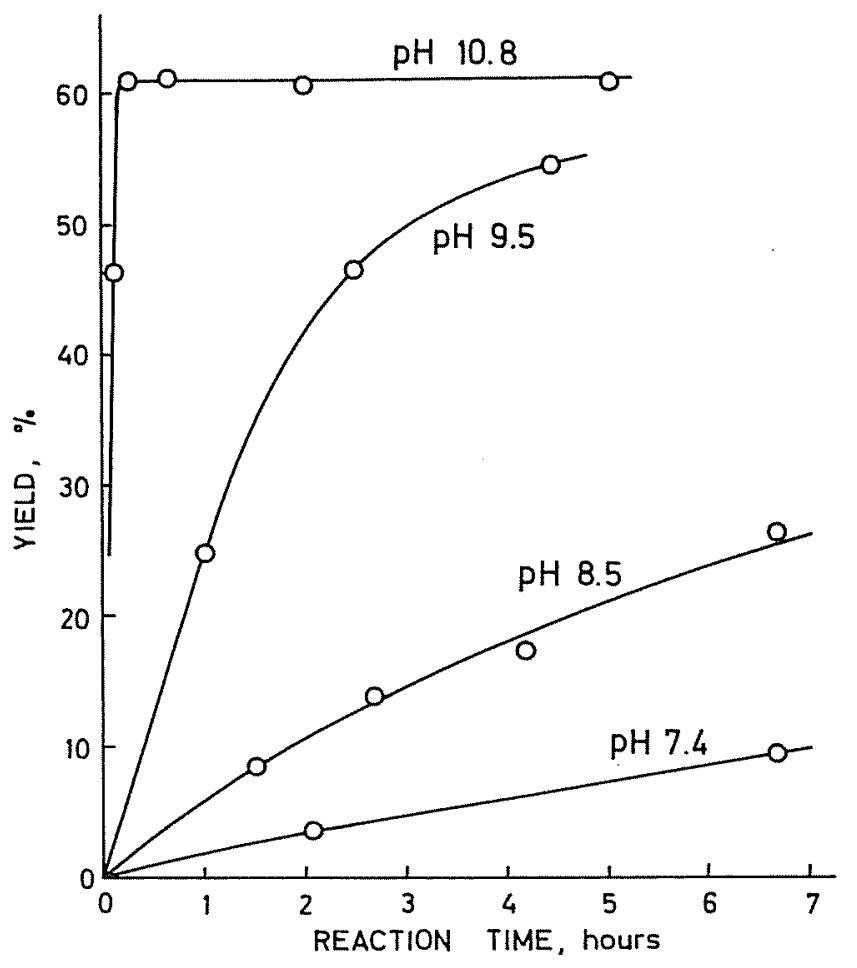

Figure 3. Formation of 2-(threo-1,2,3-trihydroxypropyl)tartronic acid from dehydroascorbic acid at $38{ }^{\circ} \mathrm{C}$ expressed as percentage by weight of the starting material.

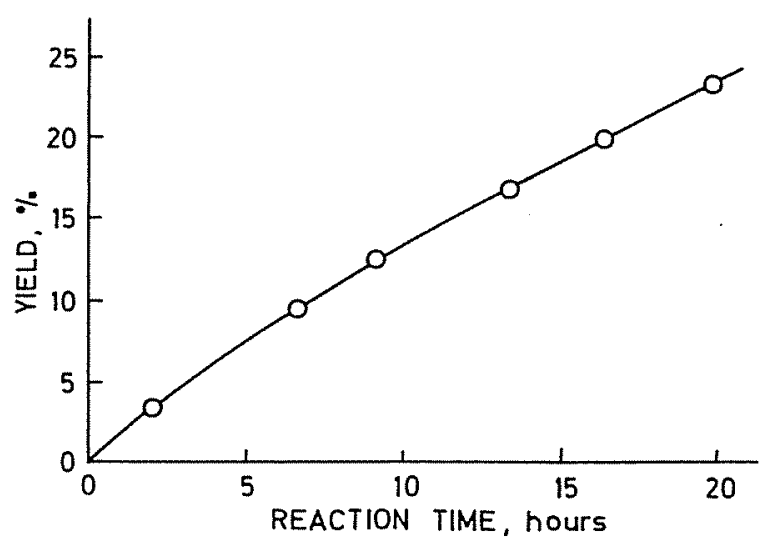

Figure 4. Formation of 2-(threo-1,2,3-trihydroxypropyl)tartronic acid from dehydroascorbic acid at physiological $\mathrm{pH}(7.4)$ and temperature $\left(38^{\circ} \mathrm{C}\right)$. 